\title{
Preconditioning of Specimens - Drying Influence on Alkali-Activated and Geopolymer Mortar
}

\author{
Vincent Trincal, Virginie Benavent, Hugo Lahalle, Gabriel Samson, Cédric Patapy, \\ Yoann Jainin and Martin Cyr
}
Laboratoire Matériaux et Durabilité des Constructions (LMDC), Université de Toulouse, INSA/UPS Génie Civil, 135 avenue de Rangueil, 31077 Toulouse cedex 04, France vincenttrincal@gmail.com

\begin{abstract}
Alkali-activated materials (AAM) are now seriously considered by the cement industry as an economical alternative to Portland cement, especially for its low $\mathrm{CO}_{2}$ footprint. However, their durability still remain to be assessed in more details. The aim of this study is to focus on the sample preconditioning conditions required for testing, especially the drying stage involved in most of the current tests. Four alkali-activated binders were studied: a geopolymer (Na-silicate activated metakaolin), a Na-carbonate activated slag (GGBS), a Na-silicate activated slag and a Na-silicate activated mixture of 50\% metakaolin with 50\% GGBS. After an endogenous cure of 28 days at $20^{\circ} \mathrm{C}$, mortar specimens were dried at different temperatures (from $20^{\circ} \mathrm{C}$ to $125^{\circ} \mathrm{C}$ ) until mass stabilization. Drying kinetics and released water contents were evaluated, as well as physical, mechanical and mineralogical analyses at the end of drying. Optimal drying temperature for each alkali-activated binder was determined by coupling mechanical strength measurements and mercury intrusion porosimetry. This study revealed that an inappropriate drying temperature could modify the porosity of some classes of AAM, and reduced the compressive strength by up to 30 to $40 \%$. Antagonistic behaviors were observed in the four alkali-activated materials studied, therefore one should be careful about selecting preconditioning protocols for assessing the properties and the durability of these binders.
\end{abstract}

Keywords: Alkali-Activated Binder, Geopolymer, GGBS, Drying Conditions, Durability.

\section{Introduction}

Alkali-activated binders are produced from a source of aluminosilicates (precursor) mixed with a highly alkaline solution (e.g. sodium $(\mathrm{Na})$ or potassium $(\mathrm{K})$ silicate solutions) called the activating solution (Davidovits, 1991; Provis and Van Deventer, 2009). There are two main types of alkali-activated binders, based on the calcium content of the precursors. They differ from the chemical mechanism that takes place and from the reaction products. For those rich in calcium, such as ground granulated blast-furnace slag (GGBS), chemical reactions are based on dissolution/precipitation steps. The main reaction products are C-A-S-H type phases $\left(\mathrm{CaO}-\mathrm{Al}_{2} \mathrm{O}_{3}-\mathrm{SiO}_{2}-\mathrm{H}_{2} \mathrm{O}\right)$ (Pacheco-Torgal et al., 2015). For precursors with low calcium content, such as metakaolins and type F fly ashes, the term geopolymer is used (Davidovits, 1991). This time, the chemical reactions consist in a dissolution/polycondensation steps, leading to a 3D-aluminosilicate network. In this network, silicon and aluminium are IV-fold coordinated and the alkali cation plays the role of a charge-balancing ion (Rowles et al. 2007).

An abundant literature is available regarding the alkali-activated materials (AAM) formulation, but only few studies deals with durability (Luukkonen et al., 2018). Accelerated procedures for durability testing of Portland cements mixtures are often applied to AAM 
without any modification, although the raw material used and physico-chemical reactions are different. These tests usually require a preconditioning of the specimens at temperatures ranging from $45^{\circ} \mathrm{C}$ (e.g. accelerated carbonation XP-P-18-458_2008), $80^{\circ} \mathrm{C}$ (e.g. permeability XP-P-18-463_2011), or even at $105^{\circ} \mathrm{C}$ (e.g. porosity NF-EN-18-459_2010). Alkali-activated binders contain gels and hydrates that can be affected and even destroyed at these temperatures (e.g. Zhang et al., 2019). Thus, the effects of the preconditioning conditions on AAM need to be assessed, in order to avoid a deterioration of the specimens that could lead to misleading interpretations of durability tests.

\section{Material and Methods}

\subsection{Samples Preparation}

The raw materials used are Argicem metakaolin from the ARGECO Company; GGBS from ECOCEM; Betol 47T Na-silicate solution from Woellner $\left(\mathrm{SiO}_{2} / \mathrm{Na}_{2} \mathrm{O}=1.7\right)$, Na-carbonate powder $\left(\mathrm{Na}_{2} \mathrm{CO}_{3}\right)$ from Solvay, tap water from Toulouse city and standardized sand (NF EN 196-1 2016 and ISO 679 2009). Metakaolin and GGBS properties are available elsewhere in literature (e.g. Sabir et al., 2001; Pouhet and Cyr, 2015; Pouhet and Cyr, 2016a; Samson et al., 2017a).

Four alkali-activated mortars with a water/binder ratio of 0.4 were studied (see Table 1). The first formula is a metakaolin-based geopolymer developed by Pouhet et al. and which has

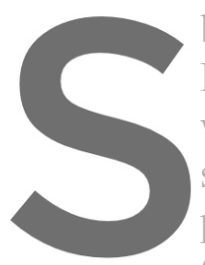
been the subject of several publications (Pouhet and Cyr, 201 Pouhet, 2015a; 2015b; with either a $\mathrm{Na}$-Carbon silicates). Finally, a mir proposed in this study (based on Ca or $\mathrm{Na}$ ). This formula has been previousiy tested on paste (Samson et al., 2017a).

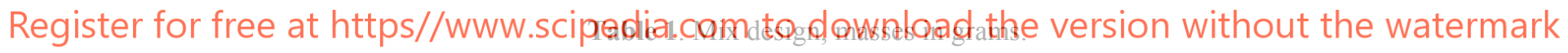

\begin{tabular}{ccccccc}
\hline & Metakaolin & GGBS & Na-silicate & Na-carbonate & Tap water & Sand \\
\hline Geopolymer & 450 & & 354.9 & & 46.2 & 1350 \\
\hline GGBS-silicates & & 450 & 101.3 & & 141.8 & 1350 \\
\hline GGBS-carbonates & & 450 & & 45 & 198 & 1350 \\
\hline Mk-GGBS-silicates & 225 & 225 & 228.1 & & 94 & 1350 \\
\hline
\end{tabular}

Mortar specimens $4 \times 4 \times 16 \mathrm{~cm}^{3}$ were made according to the standard protocol NF EN 1961_2016. Most of samples were demolded 24 hours after pouring, except the GGBS-carbonates formula which was demolded at 48 hours because of its low mechanical properties at early age. The specimens were then endogenously cured (wrapped in plastic film and sealed in humidified plastic bags) for 28 days at $20^{\circ} \mathrm{C}$. After this cure, some samples were kept in endogenous conditions, other were dried in different environments $\left(20^{\circ} \mathrm{C}-95 \% \mathrm{RH}, 20^{\circ} \mathrm{C}\right.$ $50 \% \mathrm{RH}, 20^{\circ} \mathrm{C}$ under vacuum, $40^{\circ} \mathrm{C}, 60^{\circ} \mathrm{C}, 80^{\circ} \mathrm{C}, 105^{\circ} \mathrm{C}$ and $125^{\circ} \mathrm{C}$ ). Depending on the drying rate, the mortar specimens were analyzed at different times (the drying time varies from 12 to 49 days) and most of them at 60 days, and then compared to the mortar specimens kept in endogenous conditions for each due date. As regards the geopolymer specimens 
placed in the vacuum desiccator, the pump operated only during laboratory's office hours ( 8 hours a day, otherwise the vacuum was maintained over the test period).

\subsection{Characterizations}

Several analyses were carried out in order to assess the effect of drying on the four alkaliactivated materials:

- Mass monitoring was performed until mass stabilization, i.e. until the mass loss is less than $0.01 \%$ between 7 consecutive days (except with $20^{\circ} \mathrm{C}-50 \% \mathrm{RH}$ conditions which would take months to dry).

- Compressive strengths were determined using a standardized 3R press (NF EN 1961_2016). Three measurements per mortar prism were made using a ramp of $5 \mathrm{kN} /$ second. Measurements were carried out on the dry specimens as well as on control ones stored under endogenous conditions over the same period. In order to evaluate the dispersion of data, three specimens by drying condition were analyzed for each formula.

- Mercury intrusion porosimetry was performed using an AutoPore IV 9500 Porosimeter from Micromeritics according to the ISO 15901-1_2005 standard. Unlike what is recommended in the standard, samples did not undergo pretreatment for mercury intrusion analysis (i.e. $110^{\circ} \mathrm{C}$ heating in a vacuum oven at $3 \mathrm{~Pa}$ for $4 \mathrm{~h}$ ). Endogenous samples containing water are therefore not dried, but dehydrated during evacuation step in the porosimeter. In order to be consistent for all samples, the test did not start until the exhaust pressure was $\leq 50 \mu \mathrm{mHg}$ assuming
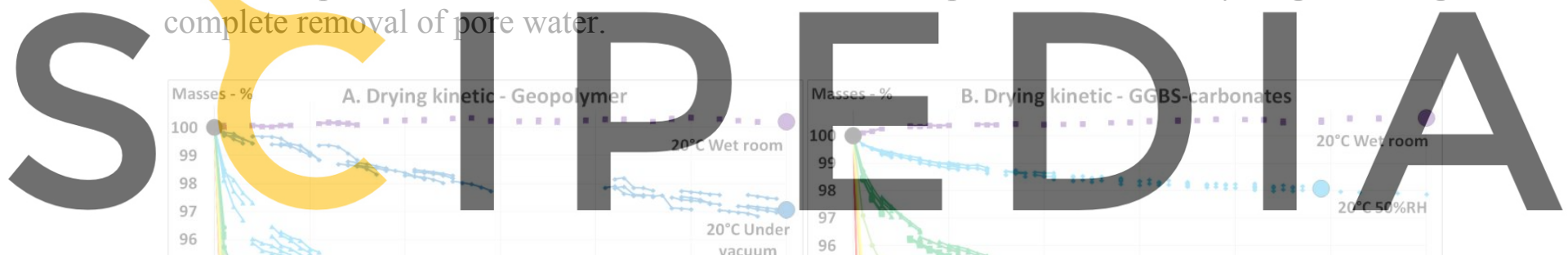

Register fogr free at https//www.scipedia.com to
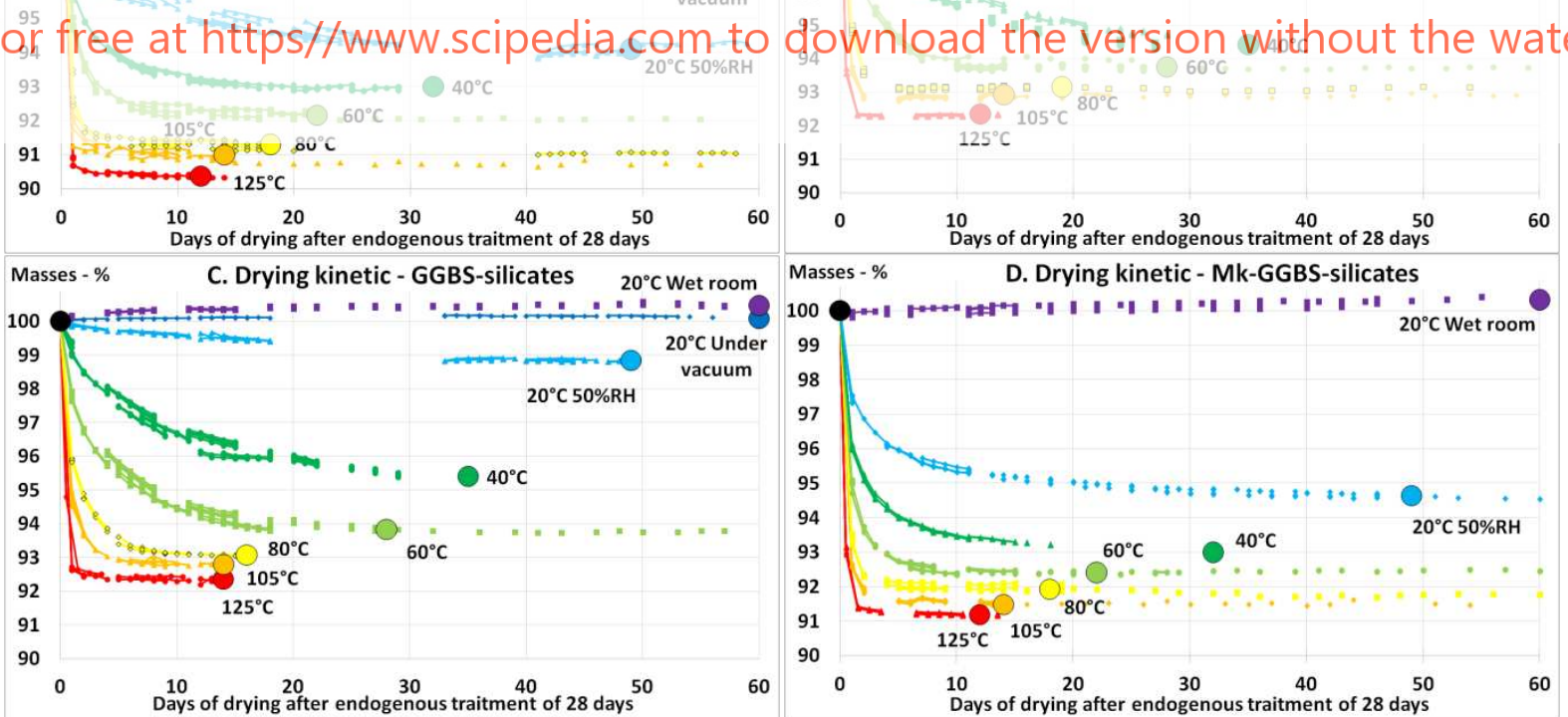

Figure 1. Mass evolution during drying at different temperatures of Geopolymer (A), GGBS-silicates (B), GGBS-carbonates (C) and Mk-GGBS-silicates (D). The circles represent the mass stabilization point. 


\section{Results and Discussion}

\subsection{Mass Monitoring}

The mass variations recorded during the different drying processes show that the higher the temperature, the faster and more important the drying process (Figure 1). The comparison between the four materials shows different drying kinetics and different water content trapped in the structure of the material depending on the type of AAM. The drying rate is quicker when metakaolin is used as a precursor (Figures 1A and 1D), especially at lower temperatures, i.e. $20^{\circ} \mathrm{C}, 40^{\circ} \mathrm{C}$ and $60^{\circ} \mathrm{C}$. Besides, almost all the mixing water has been evaporated in geopolymers at $105^{\circ} \mathrm{C}$ while almost $8 \%$ is remaining in GGBS-silicates (results not shown here). This can be explained because in geopolymers, all the water initially introduced is located in the porosity of the materials or in the alkali hydration sphere in the structural cavities of the Si-Al network (Rowles et al., 2007), while in GGBS systems part of the water is bound in reaction products $(\mathrm{C}-\mathrm{A}-\mathrm{S}-\mathrm{H})$.

\subsection{Mechanical Compressive Strengths}
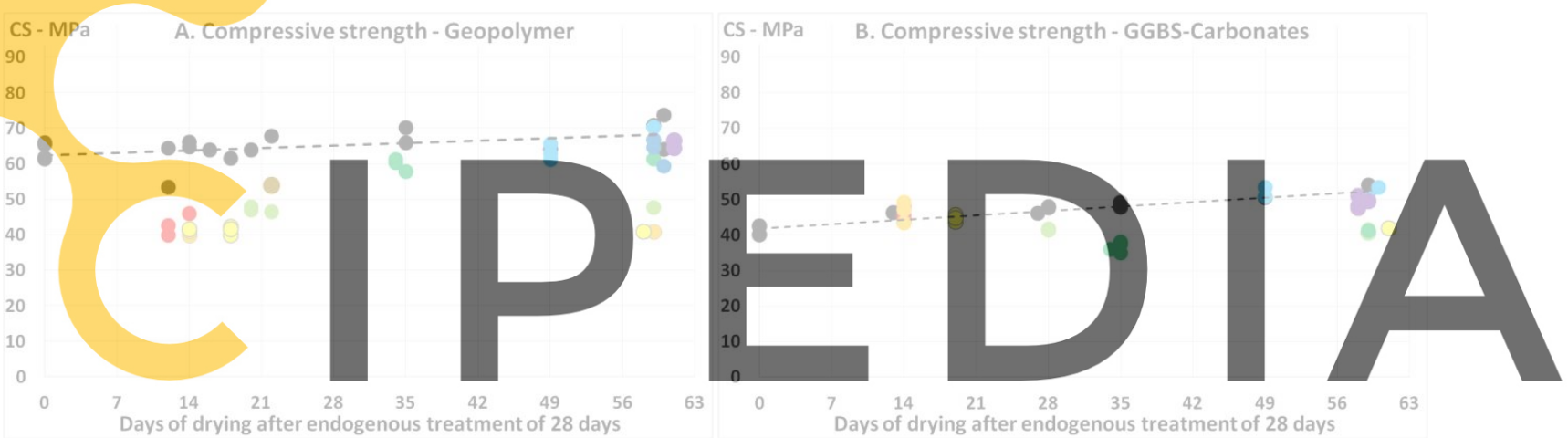

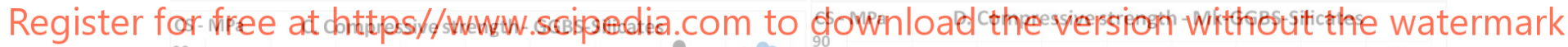

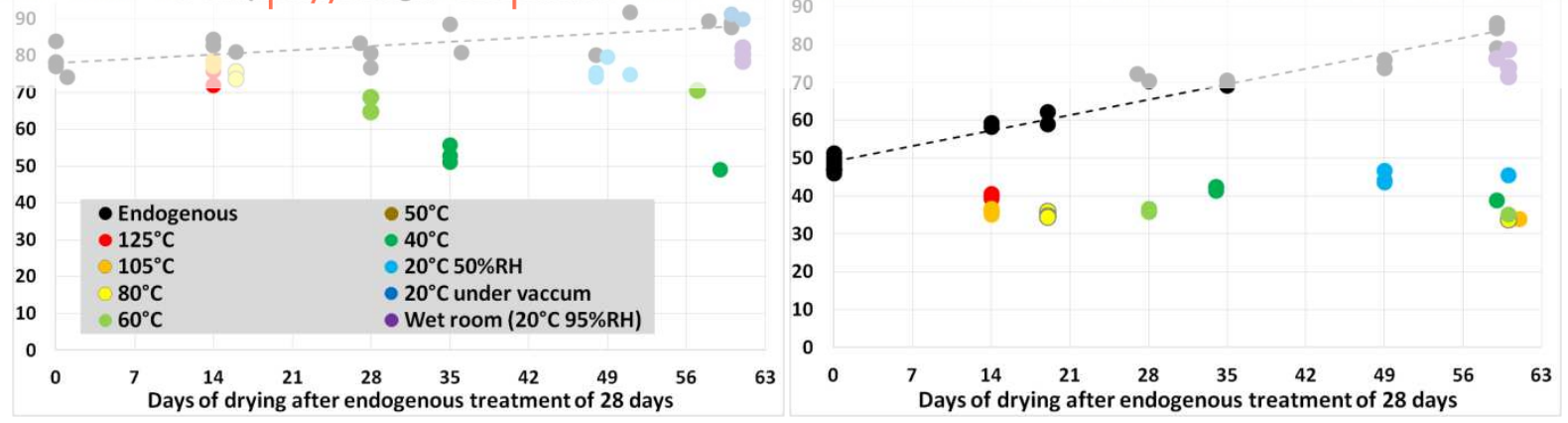

Figure 2. Compressive strengths (CS) of mortars cured in endogenous conditions (black spots) or dried at different temperatures (after endogenous treatment of 28 days). Geopolymer (A), GGBS-carbonates (B), GGBSsilicates (C) and Mk-GGBS-silicates (D). The legend inserted in $\mathrm{C}$ is valid for all figures.

In endogenous conditions, geopolymer samples show a slow increase of mechanical compressive strengths (CS) from $61 \pm 6 \mathrm{MPa}$ at 28 days to $70 \pm 5 \mathrm{MPa}$ at 88 days (Figure 2A). This increase seems to be stabilized after three months, as confirmed by six-months sample analyses. For GGBS-carbonates and GGBS-silicates, CS start from $41 \pm 2 \mathrm{MPa}$ and 
$77 \pm 6 \mathrm{MPa}$ at 28 days, respectively, then reach $54 \pm 2 \mathrm{MPa}$ and $89 \pm 4 \mathrm{MPa}$ two months later (Figure 2B-C). The CS increase is greater than for the geopolymer, and seems stabilized beyond 6 months. CS of the Mk-GGBS-silicates formulation increase from $49 \pm 1 \mathrm{MPa}$ at 28 days to $75 \pm 4 \mathrm{MPa}$ at 77 days (Figure 2D). To conclude, all four formulations show a progressive CS increase during the first months in endogenous conditions, probably linked to the pursue of chemical processes with time.

When the mortar specimens are dried (after endogenous curing for 28 days), the mechanical strength depends on both formula and drying conditions. For a drying temperature $\geq 50^{\circ} \mathrm{C}$, geopolymer shows an important CS loss (up to - $36 \%$ ), even if the temperature conditions are extended for several weeks (Figure 2A). On the other hand, at drying temperature $\leq 40^{\circ} \mathrm{C}$, CS were similar to endogenous ones. For GGBS-carbonates and GGBSsilicates, drying with temperature $\geq 80^{\circ} \mathrm{C}$ or at $20^{\circ} \mathrm{C}$ (with several humidities) does not decrease the $\mathrm{CS}$, which are similar to those of samples stored under endogenous conditions (Figure 2B-C). However, drying at $60^{\circ} \mathrm{C}$ or more significantly at $40^{\circ} \mathrm{C}$ decreases the CS up to $-24 \%$ and -29\% for GGBS-carbonates and GGBS-silicates, respectively. As for geopolymer, when the drying is maintained for a longer period than required, CS do not evolve anymore whereas in endogenous conditions the CS slightly increases, probably due to the wet storage that enable the further reaction of the materials. Finally, drying of the Mk-GGBS-silicates formulation considerably reduce CS (from - 30\% to - 50\%) whatever the temperature used (Figure 2D). Only samples cured in wet room $\left(20^{\circ} \mathrm{C} 95 \% \mathrm{RH}\right)$ retain similar mechanical strengths before and after

\subsection{Hg Porosity}

In endogenous conditior

between 28 and 88 diys.

Mean porosity is closed
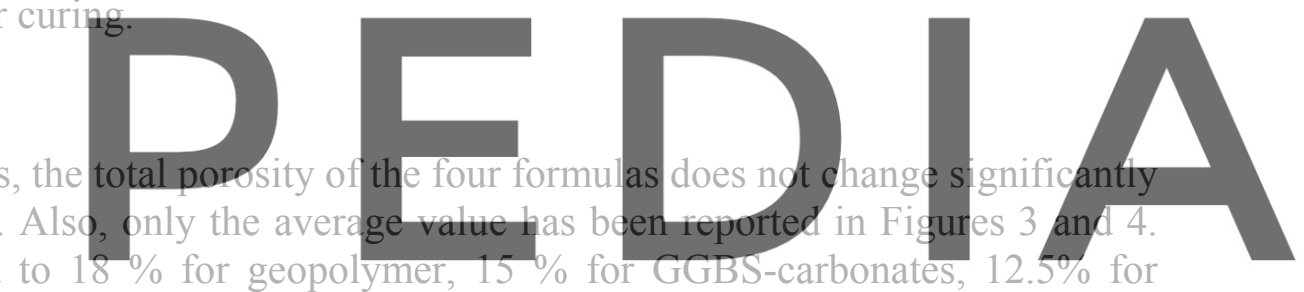

GGBS-silicates and 15.5\% for Mk-GGBS-silicates. GGBS blends therefore have a lower

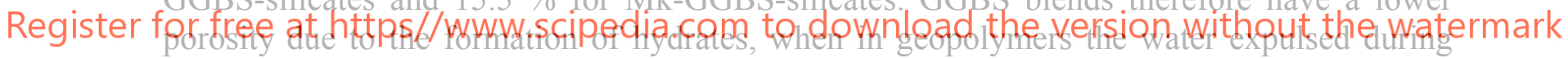

condensations reactions is responsible for more porosity.

In drying conditions, the total porosity evolves differentiy for each system, as it seems to increase with the temperature level for the geopolymer (Figure 3A, 3B and 4A), to be quite stable for GGBS-carbonate (Figure 4B), having a maximum value for a drying temperature of $40^{\circ} \mathrm{C}$ as regards of GGBS-silicates (Figure 4D) and to be higher but stable for Mk-GGBSsilicates (Figure 4D).

Concerning the pore size distribution, geopolymer kept in endogenous conditions has half of the porosity attributed to pores $<10 \mathrm{~nm}$, a quarter to $10-100 \mathrm{~nm}$ and the last quarter to $>$ $100 \mathrm{~nm}$ (Figure 4A). However, this does not mean that half of the porosity is $<10 \mathrm{~nm}$, but that the access to half of the porosity is possible by a diameter lower than $10 \mathrm{~nm}$ (according to inkbottle effect, e.g. Benavent et al., 2016; Muller and Scrivener, 2017). Except desiccation under vacuum which is not an efficient drying, even a smooth drying at $20^{\circ} \mathrm{C}$ has the effect of replacing all the porosity $<10 \mathrm{~nm}$ by the category $10-100 \mathrm{~nm}$. A strong drying replaces half of the $10-100 \mathrm{~nm}$ by the $0.1-1 \mu \mathrm{m}$ and there is an increase of the $1-10 \mu \mathrm{m}$ pore size. In summary, for the geopolymer, the more intense the drying, the greater the pore size (or at least the size of the necks). 

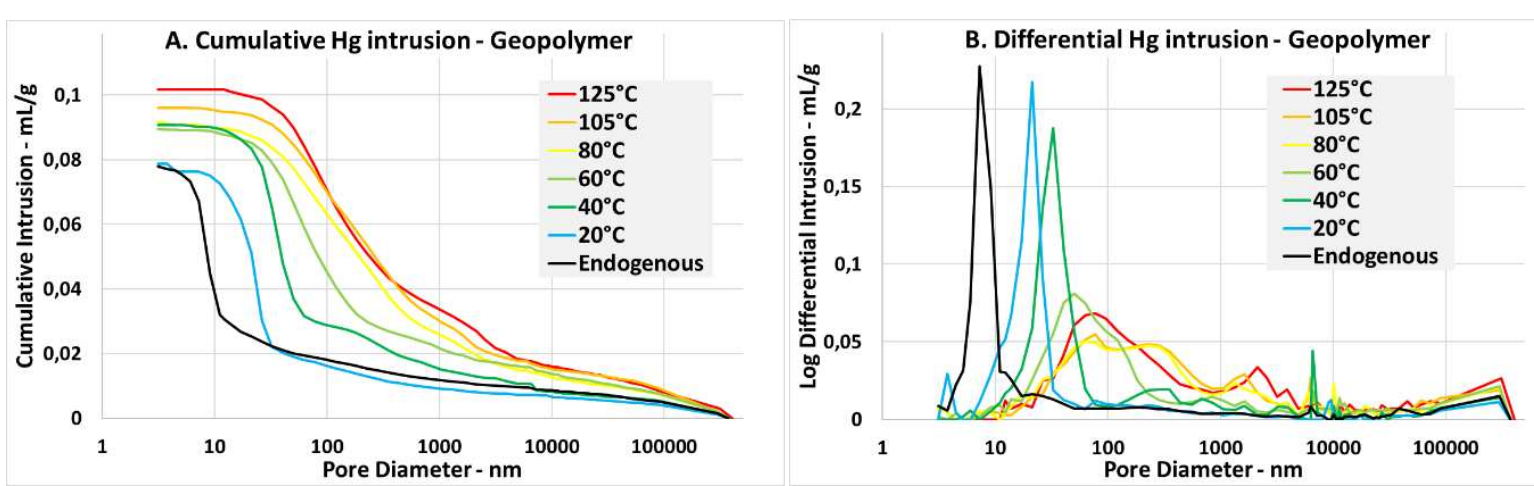

Figure 3. Geopolymer mortars mercury porosimetry as a function of drying: cumulative intrusion vs. pore diameter (A); differential intrusion vs. pore diameter (B).
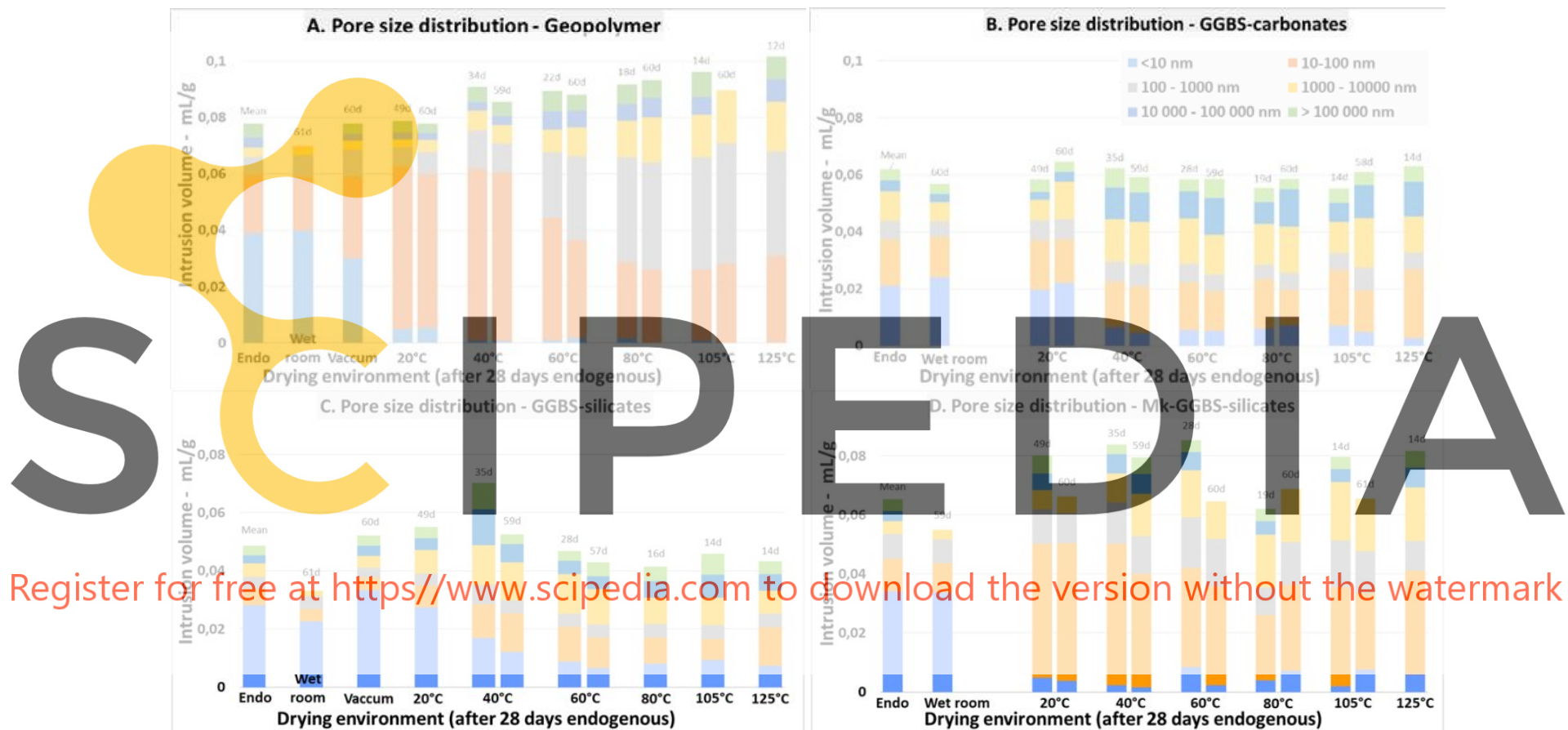

Figure 4. Pore size distribution for mortars of geopolymer (A), GGBS-carbonates (B), GGBS-silicates (C) and Mk-GGBS-silicates (D). Endo column represents the average of the samples conserved under endogenous conditions, analyzed at different ages ( 28 to 88 days), and showing similar properties. $50 \% \mathrm{RH}$ for $20^{\circ} \mathrm{C}$ column. Up to $10 \mu \mathrm{m}$ porosities are sometime missing due to porosimetry low vacuum problem.

Globally the same pore size distribution trend was observed for the other three formula, i.e. a pore size augmentation linked with drying temperature strength. However, pore size distribution modes slightly differ from one formula to another, for example with a $<10 \mathrm{~nm}$ pore contents varying from one third to half of the total porosity in endogenous conditions. Furthermore, the change in pore size family towards bigger sizes occurs starting from $20^{\circ} \mathrm{C}$ for the metakaolin materials, and from $40^{\circ} \mathrm{C}$ for the GGBS ones (Figure 4). Both geopolymer and Mk-GGBS-silicates show an evolution of the porosity with the increase of temperature from $20^{\circ} \mathrm{C}$ up to $125^{\circ} \mathrm{C}$, while this evolution is limited to the range $20-60^{\circ} \mathrm{C}$ for GGBS materials (the pore size distribution remains constant for temperatures ranging from $60^{\circ} \mathrm{C}$ to 
$125^{\circ} \mathrm{C}$ ). It should be noted, however, that the GGBS-silicates has a sharp increase in porosity for a drying temperature of $40^{\circ} \mathrm{C}$, possibly related to micro-cracking induced by mineralogical transformations as suggested on GGBS alkali-activated concrete (Azar et al., 2020).

Preconditioning recommendations must be a compromise between the drying efficiency and the impact on both the porous structure and the mechanical resistances. However, in the absence of mineralogical and microstructural data, results presented in this study should be interpreted with caution. As it has been demonstrated on Portland cements, capillary stress, the loss of physically or chemically bonded water from gels or hydrates, the potential microcracking as well as mineralogical changes within the material can lead to misestimating pore volumes (Gallé, 2000).

\section{Conclusions on Preconditioning Drying}

The effect of drying $4 \times 4 \times 16 \mathrm{~cm}$ samples at different temperatures has been assessed on four alkali-activated materials, in order to give recommendation for durability test preconditioning. The drying rate and level depend not only on the nature of the binder, in particular if chemically bonded water is present or not, but also on the porous arrangement. The results showed AAM mortars are sensitive to drying, with modifications of porosity and mechanical strengths. From mercury intrusion measurements, the pore diameter access increases starting from a drying at $20^{\circ} \mathrm{C}$ for the formula containing metakaolin as a precursor, and from $40^{\circ} \mathrm{C}$ for formula containing GGBS only.

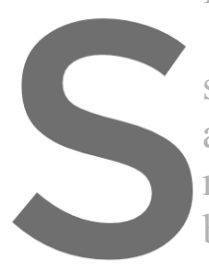

Geopolymer drying size, and affects the don affect the permeability not efficient, but does n be a drying optimum to
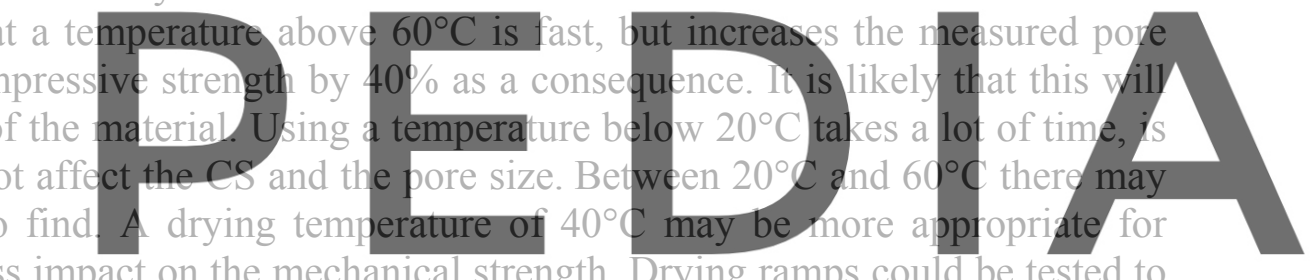

geopolymer, as it has less impact on the mechanical strength. Drying ramps could be tested to

Register for free at hof strength is due to the kinetics of drying or to the temperature.itself As regards to UGBS-carbonates and GGBS-Silcates, drying at the material should not be dried at temperature closed to $40^{\circ} \mathrm{C}$, otherwise it could lead to significant loss of mechanical strengths.

Finally, the Mk-GGBS mixture activated with silicates seems to cumulate the drawbacks of both alkali-activated systems. Whatever the temperature used, a high degree of damage to the mechanical strengths is observed, correlated with an increase of the porosity. For such mixtures, a drying by solvent exchange or by freeze-drying might be interesting, but this type of drying can only be performed on small samples.

\section{Acknowledgements}

This work is part of the L2A chair (alkali-activated binders) grouping industrial partners EDF, VINCI, ECOCEM, ARGECO, VICAT and BASF with the LMDC research laboratory.

\section{ORCID}

V. Trincal: https://orcid.org/0000-0003-4804-6617

V. Benavent: https://orcid.org/0000-0002-0263-1178

H. Lahalle: https://orcid.org/0000-0002-9201-1596 
Vincent Trincal, Virginie Benavent, Hugo Lahalle, Gabriel Samson, Cédric Patapy, Yoann Jainin and Martin $\mathrm{Cyr}$

G. Samson: https://orcid.org/0000-0002-3472-8089

C. Patapy: https://orcid.org/0000-0003-3538-7893

M. Cyr: https://orcid.org/0000-0002-5012-9131

\section{References}

Azar, P., Samson, G., Deby, F., Lahalle, H., Benavent, V., Trincal, V. and Cyr, M. (2020). Comparison of the resistance against chloride-induced corrosion between ordinary and alkali activated concrete. Presented at the ACI/RILEM international conf. on cementitious materials and alternative binders for sustainable concrete.

Benavent, V., Frizon, F. and Poulesquen, A. (2016). Effect of composition and aging on the porous structure of metakaolin-based geopolymers. Journal of Applied Crystallography, 49, 2116-2128.

Cyr, M. and Pouhet, R. (2015a). Resistance to alkali-aggregate reaction (AAR) of alkali-activated cement-based binders. In Handbook of Alkali-Activated Cements, Mortars and Concretes pp. 397-422. Elsevier.

Cyr, M. and Pouhet, R. (2015b). The frost resistance of alkali-activated cement-based binders. In Handbook of Alkali-Activated Cements, Mortars and Concretes pp. 293-318. Elsevier

Davidovits, J. (1991). Geopolymers - Inorganic polymeric new materials. Journal of Thermal Analysis and Calorimetry, 37, 1633-1656

Gallé, C. (2001). Effect of drying on cement-based materials pore structure as identified by mercury intrusion porosimetry: a comparative study between oven-, vacuum-, and freeze-drying. Cement and Concrete Research, 31, 1467-1477.

ISO 679 (2009). Cement — Test methods — Determination of strength.

ISO 15901-1 (2005). Evaluation of pore size distribution and porosimetry of solid materials by mercury porosimetry and gas adsorption.

Luukkonen, T., Abdollahnejad, Z., Yliniemi, J., Kinnunen, P. and Illikainen, M. (2018). One-part alkaliactivated materials: A review. Cement and Concrete Research, 103, 21-34.

Muller, A.C.A. and Scrivener, K.L. (2017). A reassessment of mercury in with 1 H NMR relaxome

NF EN 196-1 (2016). Méthor

NF P 18-458 (2008). Essai

NF EN 18-459 (2010). Essai
Pacheco-Torgal, F., Labrinc Activated Cements, Mortars and Concretes. Elsevier
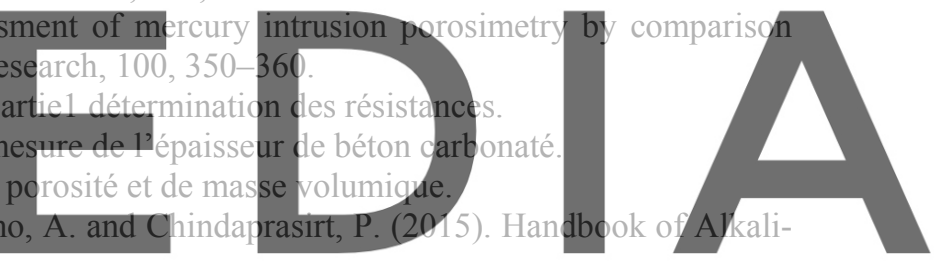

Pouhet, R. and Cyr, M. (2014). Studies of Natural and Accelerated Carbonation in Metakaolin-Based

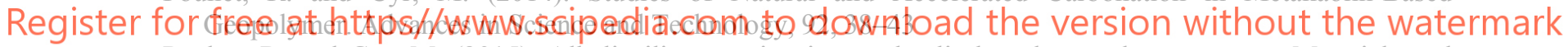

Pouhet, R. and Cyr, M. (2015). Alkali-silica reaction in metakaolin-based geopolymer mortar. Materials and Structures, 48, 571-583.

Pouhet, R. and Cyr, M. (2016a). Carbonation in the pore solution of metakaolin-based geopolymer. Cement and Concrete Research, 88, 227-235.

Pouhet, R. and Cyr, M. (2016b). Formulation and performance of flash metakaolin geopolymer concretes. Construction and Building Materials, 120, 150-160.

Pouhet, R., Cyr, M. and Bucher, R. (2019). Influence of the initial water content in flash calcined metakaolinbased geopolymer. Construction and Building Materials, 201, 421-429.

Provis, J.L. and van Deventer, J.S.J. (2009). Geopolymers: structures, processing, properties and industrial applications. Elsevier.

Rowles, M.R., Hanna, J.V., Pike, K.J., Smith, M.E. and O'connor, B.H. (2007). 29 Si, 27 Al, 1 H and 23 Na MAS NMR study of the bonding character in aluminosilicate inorganic polymers. Applied Magnetic Resonance, 32, 663.

Sabir, B.B., Wild, S. and Bai, J. (2001). Metakaolin and calcined clays as pozzolans for concrete: a review. Cement and Concrete Composites, 23, 441-454.

Samson, G., Cyr, M. and Gao, X.X. (2017). Formulation and characterization of blended alkali-activated materials based on flash-calcined metakaolin, fly ash and GGBS. Const. and Building Materials, 144, 50-64.

XP P 18-463 (2011). Bétons - Essai de perméabilité aux gaz sur béton durci.

Zhang, Z., Zhu, Y., Zhu, H., Zhang, Y., Provis, J.L. and Wang, H. (2019). Effect of drying procedures on pore structure and phase evolution of alkali-activated cements. Cement and Concrete Composites, 96, 194-203. 